\title{
EVOLUÇÃO DO CRESCIMENTO DO CAFEEIRO (Coffea arabica L.) IRRIGADO E NÃO IRRIGADO EM DUAS DENSIDADES DE PLANTIO ${ }^{1}$
}

\author{
Coffee tree (Coffea arabica $\mathbf{L}$.) growth at high and low planting densities \\ under different irrigation regimes
}

\author{
Carlos Henrique Mesquita de Carvalho ${ }^{2}$, Alberto Colombo 3 , Myriane Stella Scalco ${ }^{4}$, \\ Augusto Ramalho de Morais ${ }^{5}$
}

\begin{abstract}
RESUMO
Com este trabalho, objetivou-se avaliar o crescimento do cafeeiro, cultivar Rubi- MG-1192, submetido a diferentes regimes de irrigação (sem irrigação e, com irrigações nas tensões de água no solo de 20 e $100 \mathrm{kPa}$ ) em duas densidades de plantio, 2500 plantas/ ha $(4,0 \times 1,0 \mathrm{~m})$ e 10000 plantas/ha $(2,0 \times 0,5 \mathrm{~m})$. O experimento foi conduzido em uma área experimental do Departamento de Agricultura da Universidade Federal de Lavras/MG. O delineamento experimental foi o de blocos casualizados com quatro repetições, utilizando-se o esquema de parcela subdividida, sendo as parcelas compostas pelas duas densidades de plantio e as subparcelas pelos regimes de irrigação. As características fenológicas utilizadas para descrever o crescimento dos cafeeiros foram: altura da planta, diâmetro de copa e número de ramos plagiotrópicos por planta. Foram efetuadas avaliações trimestrais, por um período de dois anos, oito meses e 20 dias (990 dias). As relações entre altura das plantas e época de avaliação e enrtre diâmetro de copa e época de avaliação apresentaram comportamento assintótico. A relação entre número de ramos por planta e época de avaliação foi linear. Os tratamentos irrigados apresentaram uma maior altura de plantas, um maior diâmetro de copas e maior número de ramos plagiotrópicos que os não irrigados. A densidade de plantio não afetou o diâmetro de copas, mas as plantas mais altas e com maior número de ramos plagiótropicos foram observadas na maior densidade de plantio.
\end{abstract}

Termos para a indexação: Cafeicultura irrigada, densidade de plantio do café, crescimento do cafeeiro, Coffea arabica.

\begin{abstract}
This study had the objective of evaluating growth of coffee trees (cv. Rubi-MG1192) submitted to different irrigation regimes (not irrigated and irrigated at soil water tension of 20 and $100 \mathrm{kPa}$ ) and two planting densities: 2500 plants/ha (4x1m spacing) and 10000 plants/ha ( $2 \times 0.5 \mathrm{~m}$ spacing). The experiment was carried out in an experimental area of the Agronomy Department of the Federal University of Lavras/MG, Brazil. A randomized block experimental design, with split plots and four replications, was used. Planting density was kept in the plots and irrigation regime in the sub plots. Parameters used to describe coffee tree growth were: plant height, tree canopy diameter, and number of plagiotropic branches per plant. Measurements were taken every three months, during 990 days (two years eight months and 20 days). Plant height versus time and tree canopy diameter versus time relationships showed an asymptotic behavior, while number of plagiotropic branches versus time relationship was linear. Irrigated plants were taller with greater canopy diameter and higher number of plagiotropic branches per plant than not irrigated plants. Planting densities did not affect canopy tree diameter however, under the highest planting density, taller plants with the higher number of plagiotropic branches were observed.
\end{abstract}

Index terms: Irrigation, coffee, plant density.

(Recebido para publicação em 4 de agosto de 2004 e aprovado em 3 de maio 2005)

\section{INTRODUÇÃO}

Na última década, a cafeicultura brasileira sofreu mudanças que potencializaram a busca por sistemas altamente tecnificados, que incorporam avanços técnicos e empresariais. Dentre esses avanços, destaca-se a utilização da irrigação que, segundo Mantovani (2000), além de proporcionar maior produtividade e melhor qualidade do produto, poderá proporcionar menores riscos e maior eficiência na utilização e aplicação de insumos.
Apesar da maior ocorrência de cafeicultura irrigada em regiões onde existem maiores restrições hídricas, é grande também a implantação de projetos de irrigação em áreas tradicionais de cafeicultura, como nas regiões Sul e da Zona da Mata de Minas Gerais, além de diversas regiões do Estado de São Paulo (MANTOVANI \& SOARES, 2003).

De acordo com Alves (1999), a implantação da irrigação em áreas tradicionais de cafeicultura é justificada tanto na região Sul de Minas, como em outras também consideradas climaticamente livres de déficit hídrico para

\footnotetext{
${ }^{1}$ Projeto financiado pelo CBP\&D/Café/EMBRAPA (Proj. 19.2002.316.02)

${ }^{2}$ Engenheiro Agrônomo, Mestrando do Departamento de Agricultura da Universidade Federal de Lavras/UFLA - Cx. P. 3037 - 37.200-000 - Lavras, MG.

${ }^{3}$ Professor Adjunto do Departamento de Engenharia da Universidade Federal de Lavras/UFLA - Cx. P. 3037 - $37.200-000$ - Lavras, MG.

${ }^{4}$ Pesquisadora do Departamento de Agricultura da Universidade Federal de Lavras/UFLA - Cx. P. 3037 - 37.200-000 - Lavras, MG - msscalco@ufla.br

${ }^{5}$ Professor Titular do Departamento de Ciências Exatas da Universidade Federal de Lavras/UFLA - Cx. P. 3037 - 37.200-000 - Lavras, MG.
} 
o cafeeiro, pelo fato destas sofrerem na maioria das vezes o efeito de estiagens prolongadas nos períodos críticos de demanda de água pelo cafeeiro. A ocorrência de déficis hídricos que comprometem a produção das lavouras cafeeiras na região Sul de Minas Gerais foi comprovada por meio de respostas positivas observadas com o uso da irrigação nesta região. Faria et al. (2001), Karasawa (2001) e Karasawa et al. (2001), em Lavras/MG, observaram que o aumento da lâmina de irrigação até $120 \%$ da evaporação do tanque "Classe A" aplicada melhoram algumas características de crescimento (altura das plantas e diâmetro de copa) e produção do cafeeiro.

Para quantificar adequadamente as necessidades de água de uma lavoura, é preciso considerar que as relações hídricas do cafeeiro são alteradas pela densidade de plantio utilizada. Nos espaçamentos tradicionais é observada uma maior carga de radiação por planta, porém a cobertura vegetal incompleta pode promover uma maior perda de água, tanto por lixiviação quanto por evaporação. Nos espaçamentos adensados, observa-se o oposto, a menor radiação por planta pode reduzir a sua demanda hídrica, mesmo quando o consumo geral é maior (MELO et al., 2003). Gathara \& Kiara (1995), com base em estudos realizados no Kenya, verificaram que a irrigação e os menores espaçamentos de plantas aumentou o crescimento vegetativo, reduzindo a transmissão de luz no dossel das plantas, causando alterações na produção das plantas. No caso específico do Brasil, o desenvolvimento do cafeeiro não irrigado sob diferentes densidades de plantio tem sido objeto de vários estudos. No entanto, estudos sobre os efeitos da irrigação do cafeeiro em diferentes sistemas de adensamento de plantio ainda são recentes (FURLANI JÚNIOR \& MOREIRA, 2001; MELO et al., 2003).

Com o presente trabalho, objetivou-se analisar desde o plantio das mudas no campo e durante 990 dias, o efeito de diferentes regimes de irrigação e densidades de plantio na evolução das características fenológicas como a altura de plantas, diâmetro de copa e o número de ramos plagiotrópicos do cafeeiro.

\section{MATERIAL E MÉTODOS}

O experimento foi conduzido, no período de fevereiro de 2001 a dezembro de 2003, na área experimental do Departamento de Agricultura da Universidade Federal de Lavras/MG, onde foram plantadas mudas de cafeeiro da cultivar Rubi MG-1192. De acordo com a classificação de Köppen (1970), o clima do local é do tipo $\mathrm{C}_{\mathrm{w}} \mathrm{a}$, caracterizado por duas estações distintas: uma seca, de abril a setembro, e outra chuvosa, de outubro a março. As médias anuais de temperatura, precipitação e umidade relativa são, respectivamente, $19,4^{\circ} \mathrm{C}, 1529,7 \mathrm{~mm}$ e $76,2 \%$. O solo da área experimental foi classificado como Latossolo Vermelhodistroférico.

Foi utilizado um delineamento experimental em blocos casualizados e parcelas subdivididas em quatro repetições. As características fenológicas do cafeeiro (altura de planta, diâmetro de copa e número de ramos plagiotrópicos por planta) foram analisadas como parcelas subdivididas no tempo. Duas densidades de plantio, 2500 plantas/ha $(4,0 \times 1,0 \mathrm{~m})$ e 10000 plantas/ha $(2,0 \times 0,5 \mathrm{~m})$, foram implantadas nas parcelas sob duas tensões de irrigação, 20 e $100 \mathrm{kPa}$, mais uma testemunha sem irrigação (SI) nas subparcelas, perfazendo um total de 6 tratamentos com 8 plantas úteis cada. As avaliações de crescimento iniciaram-se 3 meses após o plantio e foram repetidas trimestralmente por um período de 990, perfazendo um total de 10 avaliações. O método dos quadrados mínimos foi utilizado para ajustar os parâmetros das equações que descrevem as características de crescimento do cafeeiro em função das épocas de avaliações para as diferentes combinações de densidade de plantio e regime de irrigação.

Uma linha lateral de gotejadores autocompensantes, com vazão de 3,75 litros/hora, espaçados de $0,4 \mathrm{~m}$ ao longo da linha, foi utilizada para a irrigação das subparcelas. A umidade do solo nas subparcelas irrigadas foi monitorada por meio de tensiômetros e blocos resinados de gesso, instalados nas profundidades de 10, 25 e 40 cm, cuja descrição e forma de uso são relatados por Gomide (1998) e Silveira \& Stone (1994 ). Nos tratamentos em que as tensões de irrigação superaram a indicada para o uso do tensiômetro ( $80 \mathrm{kPa})$, utilizou-se os blocos resinados de gesso previamente calibrados. As irrigações de cada subparcela ocorreram quando as leituras da tensão da água do solo na profundidade de $25 \mathrm{~cm}$ indicavam um valor próximo ao da tensão de irrigação relativa àquele tratamento (20 ou $100 \mathrm{kPa})$.

\section{RESULTADOS E DISCUSSÃO}

Na Tabela 1, apresenta-se o número de horas de operação dos gotejadores e a lâmina de água aplicada nas subparcelas irrigadas. Para uma mesma tensão de irrigação (20 ou $100 \mathrm{kPa}$ ), foi observada uma grande diferença entre os valores das lâminas aplicadas nas duas densidades de plantio. A diferença das lâminas contrastou-se com a proximidade dos valores do número total de horas de operação. A proximidade do número de horas de operação dos gotejadores indicou que, ao final dos 990 dias de estudo, o consumo de água por metro de linha de plantio 
foi praticamente o mesmo nos dois espaçamentos entre plantas (0,5 e 1,0 m) estudados. Dessa forma, concluiu-se que a redução no espaçamento entre as linhas de plantio (de 4,0 m para 2,0 m) causou um maior impacto no consumo de água por unidade de área que a redução no espaçamento entre as plantas na linha de plantio (de 1,0 para 0,5 m).

A análise de variância na Tabela 2 indicou efeitos significativos $(\mathrm{P}<0,05)$ do regime de irrigação para as três características de crescimento estudadas. Por outro lado, a densidade de plantio afetou somente a altura de planta e o número de ramos. Das interações duplas apresentadas nesta tabela, apenas a interação densidade versus regime de irrigação (DE x RI) não afetou o diâmetro de copas e o número de ramos plagiotrópicos por planta. A interação tripla só não influenciou $(\mathrm{P}>0,05)$ o número de ramos plagiotrópicos por planta.

TABELA 1 - Número de horas de operação das linhas laterais e lâminas de água aplicadas nas duas densidades de plantio e nas duas tensões de irrigação. UFLA, Lavras/MG, 2004.

\begin{tabular}{cccccc}
\hline $\begin{array}{c}\text { Densidade } \\
\text { plantas/ha }\end{array}$ & Ano & \multicolumn{2}{c}{$\mathbf{2 0 ~ k P a}$} & horas & $\mathbf{~ m m}$ \\
\cline { 2 - 6 } & 2001 & horas & mm & kPa \\
\hline \multirow{3}{*}{2500} & 2002 & 104,7 & 91,5 & 8,0 & 18,9 \\
& 2003 & 83,7 & 246,6 & 87,7 & 207,2 \\
& Total & 226,9 & 197,8 & 43,8 & 103,5 \\
\hline \multirow{4}{*}{10000} & 2001 & 54,6 & 535,9 & 139,5 & 329,6 \\
& 2002 & 102,0 & 258,1 & 4,1 & 19,2 \\
& 2003 & 112,9 & 566,8 & 65,0 & 307,3 \\
& Total & 287,5 & 533,7 & 73,1 & 345,5 \\
\hline
\end{tabular}

TABELA 2 - Análise de variância das características de altura de plantas, diâmetro de copas e número de ramos plagiotrópicos. UFLA, Lavras/MG, 2004.

\begin{tabular}{lllllll}
\hline FV & GL & Altura de planta & GL & Diâm. Copa & GL & $\mathbf{N}^{\circ}$ Ramos \\
\hline Densidade (DE) & 1 & $4730.55^{* *}$ & 1 & $1150,06^{\mathrm{ns}}$ & 1 & $645,34^{*}$ \\
Erro 1 & 6 & 263.86 & 6 & 333,83 & 6 & 64,11 \\
R.Irrigação (RI) & 2 & $9898.82^{* *}$ & 2 & $17177,50^{* *}$ & 2 & $961,33^{* *}$ \\
DE $\times$ RI & 2 & $638.89^{*}$ & 2 & $363,02^{\text {ns }}$ & 2 & $24,19^{\text {ns }}$ \\
Erro 2 & 12 & 192.71 & 12 & 317,31 & 12 & 28,69 \\
Época (EP) & 10 & $60191.14^{* *}$ & 9 & $65812,80^{* *}$ & 8 & $20454,18^{* *}$ \\
Repetição $\times$ EP & 30 & $26.49^{* *}$ & 27 & $59,10^{\text {ns }}$ & 24 & $13,99^{* *}$ \\
EP $\times$ DE & 10 & $727.83^{* *}$ & 9 & $179,22^{* *}$ & 8 & $74,90^{* *}$ \\
EP $\times$ RI & 20 & $156.64^{* *}$ & 18 & $175,94^{* *}$ & 16 & $28,95^{* *}$ \\
EP $\times$ DE $\times$ RI & 20 & $29.35^{* *}$ & 18 & $93,00^{*}$ & 16 & $6,74^{\text {ns }}$ \\
Erro 3 & 150 & 5.76 & 135 & 54,45 & 120 & 5,97 \\
\hline CV 1 $(\%)$ & & 19.77 & & 19.18 & & 15.60 \\
CV 2 $\%$ CV & & 13.77 & & 18.03 & & 11.33 \\
CV 3 $(\%)$ & & 4.08 & & 8.95 & & 7.63 \\
\hline
\end{tabular}

ns, * e **: não-significativo, significativo a $5 \%$ e $1 \%$ de probabilidade respectivamente, pelos teste de F. 


\section{Altura de planta}

A evolução da altura das plantas em função das densidades de plantio, regimes de irrigação e épocas de avaliação é apresentada na Figura 1. Em todos os tratamentos, observou-se um comportamento assintótico que, conforme demonstrado pelos elevados valores dos coeficientes de ajuste mostrados nesta figura, foi bem representado pelo modelo logístico adotado. Durante todo o período analisado, plantas de maior altura foram observadas nos tratamentos irrigados. Maiores valores de altura de planta nos tratamentos irrigados foram também observados por Alves (1999) e Karasawa et al.
(2001). Plantas sem irrigação tendem a apresentar menor altura que as irrigadas, pois a restrição hídrica pode afetar os processos metabólicos do crescimento das plantas.

Nota-se, também, que a irrigação adiantou o crescimento em altura, pois as plantas irrigadas atingiram uma média de $90 \mathrm{~cm}$ por volta dos 450 dias após o plantio, enquanto as não irrigadas só atingiram esta altura por volta de 690 dias. O efeito da densidade de plantio na altura das plantas só foi observado quando as plantas atingiram altura próxima de $90 \mathrm{~cm}$. A partir desta altura, independentemente do regime de irrigação, a maior densidade de plantio resultou em plantas mais altas.

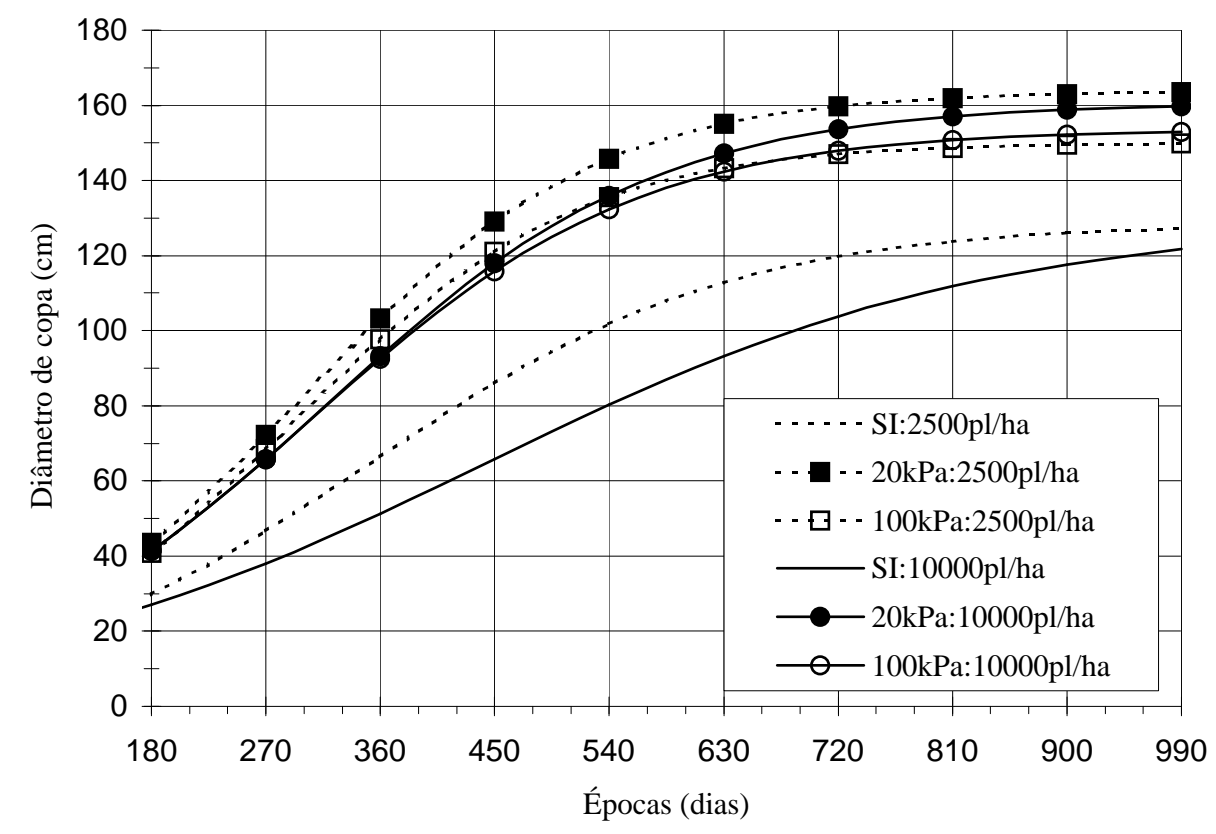

$\begin{array}{rrrrrrl}\text { SI:2500 } & y=\frac{124,1327}{1+e^{1,66415-0,003887 \cdot x}} & \mathrm{R}^{2}=95,79 \% & \mathrm{SI}: 10000 & y=\frac{133,8018}{1+e^{1,9349-0,003995 \cdot x}} & \mathrm{R}^{2}=94,11 \% \\ \text { 20:2500 } & y=\frac{139,0011}{1+e^{1,7371-0,00532 \cdot x}} & \mathrm{R}^{2}=98,12 \% & 20: 10000 & y=\frac{158,0007}{1+e^{1,9531-0,005182 \cdot x}} & \mathrm{R}^{2}=97,15 \% \\ 100: 2500 & y=\frac{136,8963}{1+e^{1,7659-0,005411 \cdot x}} & \mathrm{R}^{2}=97,97 \% & 100: 10000 & y=\frac{167,0031}{1+e^{1,9032-0,004629 \cdot x}} & \mathrm{R}^{2}=98,51 \%\end{array}$

FIGURA 1 - Altura das plantas em função das épocas de avaliação nas diferentes densidades de plantio (2 500 plantas/ ha e 10000 plantas/ha) e regimes de irrigação (sem irrigação - SI, 20 kPa e $100 \mathrm{kPa}$ ). UFLA, Lavras/MG, 2004.

Ciênc. agrotec., Lavras, v. 30, n. 2, p. 243-250, mar./abr., 2006 


\section{Diâmetro de Copa}

A evolução dos diâmetros de copas está apresentada na Figura 2. Neste caso, também ficou evidenciado que o diâmetro de copa apresentou um comportamento assintótico, conforme evidenciado pelos elevados valores do coeficiente de ajuste mostrados nesta figura, e que foi bem representado pelo modelo logístico adotado. De forma semelhante à altura das plantas, os tratamentos sem irrigação apresentaram os menores valores de diâmetro de copa. Nas duas densidades de plantio, observou-se nas curvas plotadas na Figura 2 que as plantas submetidas à tensões de $20 \mathrm{kPa}$ tenderam a apresentar maior diâmetro de copa que na tensão de 100 kPa. Na tensão de $20 \mathrm{kPa}$ as irrigações foram mais freqüentes e a tensão da água no solo foi mantida em valores mais adequados ao desenvolvimento das plantas. Vários trabalhos realizados na região Sul de Minas Gerais relataram o maior desenvolvimento das plantas com o uso da irrigação. Em um experimento na região de Lavras com cafeeiros irrigados e não irrigados, Vilella (2001) observou que o tratamento que recebeu a maior lâmina de irrigação apresentou um maior diâmetro das copas. A testemunha (sem irrigação) apresentou menor diâmetro que os demais tratamentos, confirmando as afirmações de Alves (1999), de que a irrigação propicia um aumento do diâmetro da copa do cafeeiro.

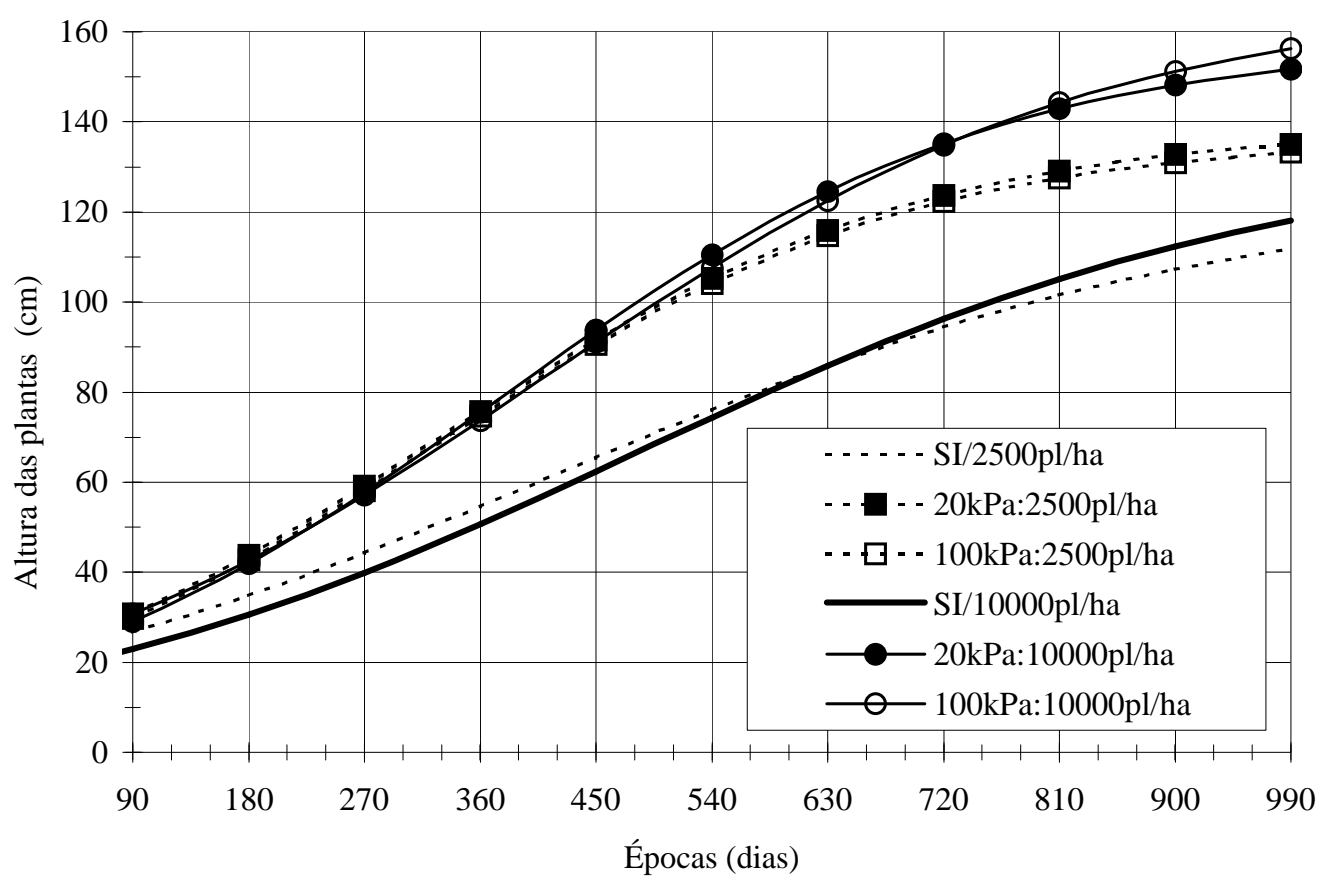

$$
\begin{array}{rlllll}
\text { SI:2500 } & y=\frac{128,5999}{1+e^{2,4577-0,007026 \cdot x}} & \mathrm{R}^{2}=94,63 \% & \mathrm{SI}: 10000 & y=\frac{129,2270}{1+e^{2,2437-0,005375 \cdot x}} & \mathrm{R}^{2}=93,99 \% \\
\text { 20:2500 } & y=\frac{163,9139}{1+e^{2,5613-0,008597 \cdot x}} & \mathrm{R}^{2}=97,02 \% & 20: 10000 & y=\frac{158,0007}{1+e^{1,9531-0,005182 \cdot x}} & \mathrm{R}^{2}=96,72 \% \\
100: 2500 & y=\frac{150,6278}{1+e^{2,6751-0,009200 \cdot x}} & \mathrm{R}^{2}=95,92 \% & 100: 10000 & y=\frac{153,7296}{1+e^{2,4069-0,007832 \cdot x}} & \mathrm{R}^{2}=96,22 \%
\end{array}
$$

FIGURA 2 - Diâmetro de copa em função das épocas de avaliação nas diferentes densidades de plantio (2 500 plantas/ ha e 10000 plantas/ha) e regimes de irrigação (sem irrigação- SI, 20 kPa e 100 kPa). UFLA, Lavras/MG, 2004. 
Nos tratamentos irrigados, a evolução dos diâmetros de copas foi praticamente igual nas duas densidades estudadas. No entanto, no tratamento não irrigado, as plantas submetidas a uma menor densidade de plantio (2 500 plantas/ha) apresentaram crescimento mais acelerado do diâmetro de copas. No final do período de avaliações, nas duas densidades, as diferenças entre os valores do diâmetro de copa das plantas não irrigadas já não eram tão acentuadas. Esses resultados diferem dos encontrados por Melo et al. (2003), que verificaram um menor diâmetro de copa com o aumento do espaçamento nas linhas de plantio.

\section{Número de ramos}

Na avaliação do número de ramos plagiotrópicos por planta, em função da ausência de resposta na interação tripla (Tabela 2), procedeu-se à análise estatística das interações duplas, fixando-se, separadamente, os níveis dos regimes de irrigação (Figura 3) e densidade de plantio (Figura 4) ao avaliar o número de ramos em função da época. Nas figuras 3 e 4, observou-se um crescimento linear, sem uma tendência de estabilização do número de ramos por planta dentro do período avaliado. Em decorrência da ausência de um comportamento assintótico, que foi observado na altura de plantas e no diâmetro de copas, adotou-se um modelo linear para representar a evolução do número de ramos em função das épocas de avaliação. Os coeficientes de ajuste das regressões foram superiores a $85 \%$, demonstrando a adequabilidade deste modelo para avaliar esta característica.

A evolução do número de ramos plagiotrópicos por planta observada nos diferentes regimes de irrigação, mostrada na Figura 3, indicou que os menores valores do número de ramos por plantas foram observados naqueles tratamentos não irrigados. Ao longo do período de avaliação, o número de ramos não variou de forma significativa entre as tensões de 20 e $100 \mathrm{kPa}$, indicando que a irrigação, mesmo em intervalos menos freqüentes, induziu a um aumento no número de ramos produtivos do cafeeiro. Esse aumento no número de ramos plagiotrópicos com a irrigação pode aumentar número de gemas, influenciando indiretamente a produção.

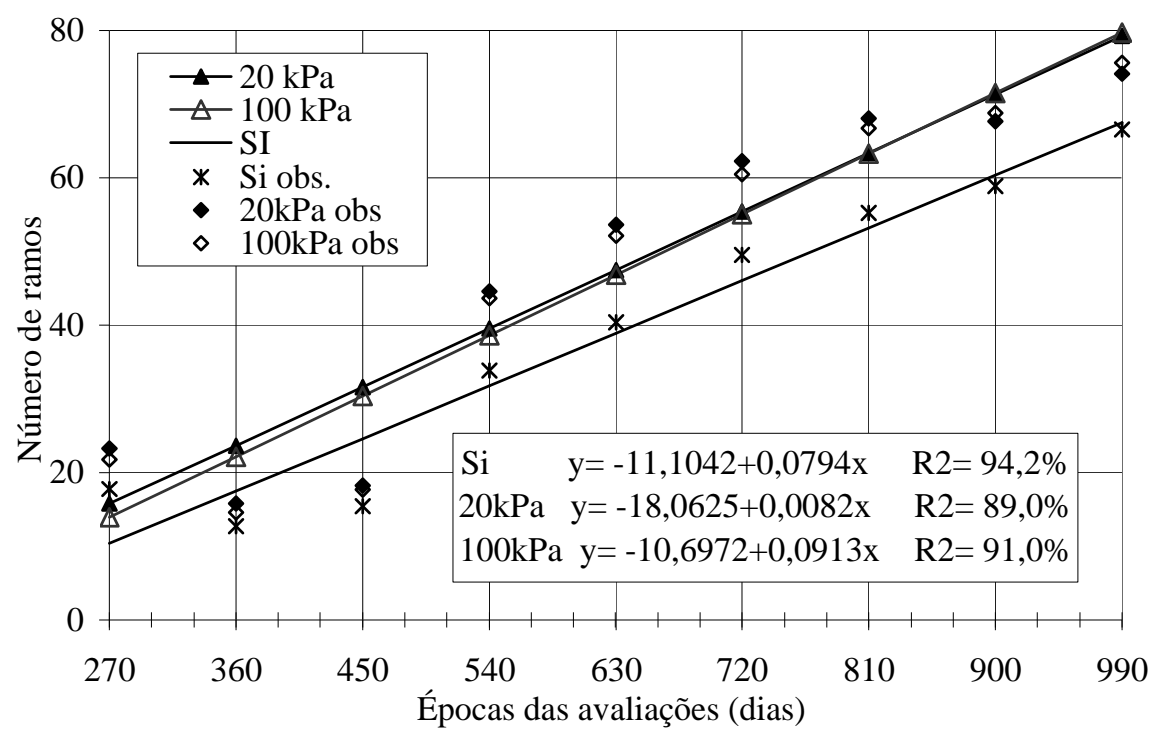

FIGURA 3 - Evolução do número de ramos plagiotrópicos por planta para cada regime de irrigação em função das épocas de avaliação. UFLA, Lavras/MG, 2004.

Ciênc. agrotec., Lavras, v. 30, n. 2, p. 243-250, mar./abr., 2006 


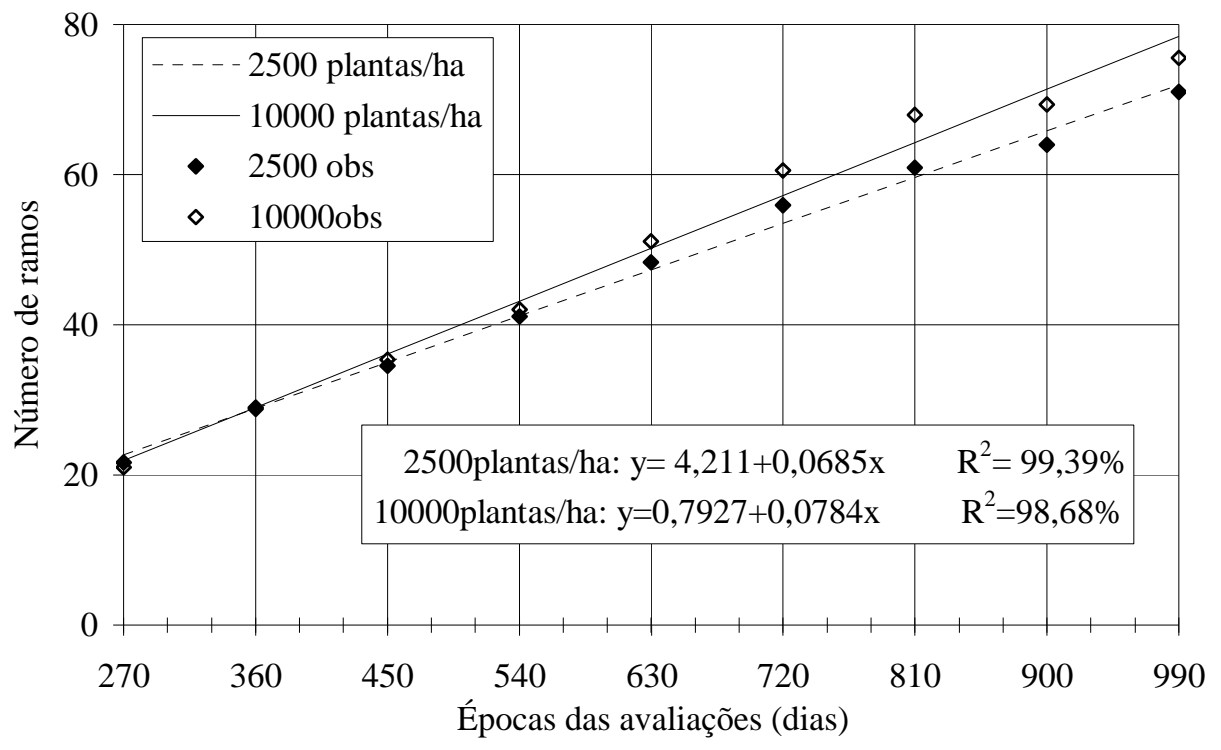

FIGURA 4 - Evolução do número de ramos plagiotrópicos por planta para cada densidade de plantio em função das épocas de avaliação. UFLA, Lavras/MG, 2004.

Acréscimos significativos no número de ramos por planta em tratamentos irrigados também foram observados por Karasawa (2001), em 770 dias de observação. Apesar de não observarem uma resposta de significância da irrigação com relação para o número de ramos, Alves (1999) e Vilella (2001) observaram uma tendência de aumento do número de ramos plagiotrópicos com o aumento na lâmina de água de irrigação.

$\mathrm{Na}$ Figura 4, pode-se observar a evolução no número de ramos sob plantio convencional (2 500 plantas/ ha) e plantio adensado (10 000 plantas/ha). Verifica-se que, a partir de aproximadamente 400 dias, o número de ramos na densidade de 10000 plantas/ha superou o número de ramos na densidade de plantio de 2500 plantas/ha. Estimouse, por meio da inclinação das retas ajustadas, que para cada 100 dias ocorreu um incremento de 7 ramos no plantio convencional e de 8 ramos plagiotrópicos por planta no plantio adensado. Com relação à altura das plantas (Figura 1) também foi observado um comportamento semelhante, pois, a partir de épocas diferenciadas em função das diferentes tensões de irrigação, as plantas na densidade de 10000 plantas/ha também superaram em altura as plantas na densidade de 2500 plantas/ha. Nacif (1997), trabalhando com espaçamentos progressivos entre as linhas de plantio
$(1,50,2,25$ e $3,00 \mathrm{~m})$ e entre plantas $(0,5,1,00,1,50 \mathrm{~m})$, observou que em plantios mais adensados ocorreram maior altura de plantas e que o número de ramos plagiotrópicos não foi afetado pelo espaçamento entre ruas que apresentou um comportamento linear negativo aos 33,3 meses de observação em relação aos espaçamento entre plantas. Como este comportamento não persistiu, o mesmo autor concluiu que esta característica não foi afetada pelo espaçamento e que a maior altura foi caracterizada por um alongamento dos entrenós e não pela diferenciação de novos ramos plagiotrópicos. Entretanto, os resultados obtidos neste trabalho indicam que as plantas apresentaram um aumento tanto em altura quanto no número de ramos, concluindo-se que ocorreu crescimento e não apenas um alongamento.

\section{CONCLUSÕES}

Apesar da Região Sul de Minas Gerais ser considerada climatológicamente livre de déficit hídrico para o cafeeiro, observou-se nesta região, tanto nos sistemas adensados de plantio (10 000 plantas/ha) quanto em sistemas tradicionais (2 500 plantas/ha), que a irrigação proporcionou um crescimento mais acentuado da altura de plantas, do diâmetro de copas e do número de ramos 
plagiotrópicos por planta.

Nas características de crescimento analisadas, apenas a altura das plantas e o número de ramos plagiotrópicos responderam aos níveis de densidade de plantio estudados, observando-se plantas mais altas e com maior número de ramos palgiotrópicos na maior densidade de plantio.

Independente do sistema de plantio ou do regime de irrigação, até 990 dias após o plantio das mudas, as relações entre altura das plantas e época de amostragem e entre diâmetro de copa época de amostragem apresentaram comportamento assintótico, enquanto a relação entre o número de ramos plagiotrópicos por planta e época de amostragem apresentou crescimento linear.

\section{REFERÊNCIAS BIBLIOGRÁFICAS}

ALVES, M. E. B. Respostas do cafeeiro (Coffea arábica L.) a diferentes lâminas de irrigação e fertirrigação. 1999. 94 p. Dissertação (Mestrado em Engenharia Agrícola) Universidade Federal de Lavras, Lavras, 1999.

FARIA, M. A.; VILELA, W. M. da C.; SILVA, M. de L. O.; GUIMARÃES, P. T. G.; SILVA, E. L. da; OLIVEIRA, L. A. M.; SILVA, A. L. da. Influência das lâminas de irrigação e da fertirrigação na produtividade do cafeeiro (Coffea arabica L.): $2^{\underline{a}}$ colheita. In: SIMPÓSIO BRASILEIRO DE PESQUISA EM CAFEICULTURA IRRIGADA, 4., 2001, Araguari-MG. Anais... Uberlândia: ICIAG/UFU, 2001. p. 1114.

FURLANI JUNIOR, E.; MOREIRA, R. C. Avaliação de espaçamentos para a cultura do café (Coffea arabica L.), com e sem emprego de irrigação suplementar, na região de Ilha Solteira-SP. In: CONGRESSO BRASILEIRO DE PESQUISAS CAFEEIRAS, 2001, Uberaba, MG. Trabalhos apresentados... Uberaba: MA/PROCAFÉ; UNIUBE; ABTEC; Fund. PROCAFÉ; CACCER, 2001. p. 361-362.

GATHARA, M. P. H.; KIARA, J. M. Factors that influence yield in close-spaced coffe. Kenya Coffee, Kenya, v. 50, n. 587, p. 387-392, 1995.

GOMIDE, R. L. Monitoramento para manejo da irrigação: instrumentação, automação e métodos. In: CONGRESSO BRASILEIRO DE ENGENHARIA AGRÍCOLA, 27., 1998, Poços de Caldas, MG. Anais... Lavras: UFLA/SBEA, 1998. p. 133-238.
KARASAWA, S. Crescimento do cafeeiro (Coffea arabica L. cv. Topázio MG-1190) sob diferentes manejos de irrigação localizada. 2001. 72 p. Dissertação (Mestrado em Engenharia Agrícola) - Universidade Federal de Lavras, Lavras, 2001.

KARASAWA, S.; FARIA, M. D.; GUIMARÃES, R. J. Desenvolvimento do cafeeiro (Coffea arabica $\mathrm{L}$.) em função do parcelamento de adubação e lâminas d'água aplicada. In: SIMPÓSIO BRASILEIRO DE PESQUISA EM CAFEICULTURA IRRIGADA, 4., 2001, Araguari, MG. Anais... Uberlândia: ICIAG/UFU, 2001. p. 25-28.

KÖPPEN, W. Roteiro para classificação climática. [S.l.: s.n.], 1970. 6 p Mimeog.

MANTOVANI, E. C. A irrigação do cafeeiro. In: ZAMBOLIM, L. Café: produtividade, qualidade e sustentabilidade. Viçosa: UFV, 2000. p. 263-290.

MANTOVANI, E. C.; SOARES, A. R. Irrigação do cafeeiro: informações técnicas e coletânea de trabalhos. Viçosa: Associação dos Engenheiros Agrícolas de Minas Gerais; UFV, 2003. $260 \mathrm{p}$.

MELO, B. de; TEODORO, R. E. F.; MARCUZZO, K. V.; GUIRELLI, J. E.; ALVARENGA, C. B. de; GONÇALVES, M. V.; SANTOS, V. B. dos. Desenvolvimento de cultivares do cafeeiro sob irrigação e em diferentes espaçamentos na linha de plantio. In: SIMPÓSIO BRASILEIRO DE PESQUISA EM CAFEICULTURA IRRIGADA, 6., 2003, Araguari, MG. Resumos expandidos... Uberlândia: UFU, 2003. p. 115-119.

NACIF, A. P. de. Fenologia e produtividade do cafeeiro (Coffea arabica L.) Catuaí sob diferentes densidades de plantio e doses de fertilizante, no cerrado de PatrocínioMG. 1997. 124 f. Tese (Doutorado em Fitotecnia) Universidade Federal de Viçosa, Viçosa, 1997.

SILVEIRA, P. M. da; STONE, L. F. Manejo da irrigação do feijoeiro: uso do tensiômetro e avaliação do desempenho do pivô central. Brasília, DF: EMBRAPA-SPI, 1994. 46 p. (EMBRAPA - CNPAF. Circular técnica, 27).

VILELLA, W. M. da C. Diferentes lâminas de irrigação e parcelamento de adubação, no crescimento, produtividade e qualidade dos grãos do cafeeiro (Coffea arábica $\mathbf{L}$.). 2001. 96 p. Dissertação (Mestrado em Engenharia Agrícola) - Universidade Federal de Lavras, Lavras, 2001. 